\title{
Estratégias de reprodução socioeconômica da agricultura familiar no cerrado
}

\section{piauiense}

\author{
Strategies for socioeconomic reproduction of family farming in the cerrado of Piauí, Brazil \\ Estrategias de reproducción socioeconómica de la agricultura familiar en el cerrado piauiense,
} Brasil

Recebido: 21/10/2021 | Revisado: 29/10/2021 | Aceito: 03/11/2021 | Publicado: 06/11/2021

Antonio Joaquim da Silva
ORCID: https://orcid.org/0000-0002-8756-9464
Instituto Federal de Educação, Ciência e Tecnologia do Piauí, Brasil
E-mail: antoniojoaquim @ifpi.edu.br
Eriosvaldo Lima Barbosa
ORCID: https://orcid.org/0000-0002-6540-460X
Universidade Federal do Piauí, Brasil
E-mail: eriosvaldobarbosa@ @otmail.com
Laudenides Pontes dos Santos
ORCID: https://orcid.org/0000-0003-4998-7419
E-mail: laudenides.pontes@ifpi.edu.br
Valdira de Caldas Brito Vieira
Instituto Federal de Educação, Ciência e Tecnologia do Piauí, Brasil
ORCID: https://orcid.org/0000-0002-1067-0628
E-mail: valdirabrito@ifpi.edu.br
Instituto Federal de Educação, Ciência e Tenologia do Piaú, Brasil
Sammya Vanessa Vieira Chaves
ORCID: https://orcid.org/0000-0002-9763-3079
E-mail: sammyachaves@ifpi.edu.br
Francisco José da Silva Júnior
Instituto Federal de Educação, Ciência e Tecnologia do Piauí, Brasil
ORCID: https://orcid.org/0000-0002-5822-1442
E-mail: engenheiro.fco.junior@gmail.com

\section{Resumo}

Este artigo pretende examinar como os agricultores familiares de Uruçuí, Piauí, marcados por um patrimônio de saberes e práticas tradicionais que se ajustam à modernidade, constroem as suas estratégias de reprodução econômica para o atendimento das suas necessidades de produção e consumo, haja vista o município se consolidar nas atividades do agronegócio globalizado, o que tem causado incertezas sobre o futuro do trabalho agrícola familiar. A análise se embasa no método etnográfico, por meio de observações sistêmicas e aplicação de entrevistas semiestruturadas com 254 agricultores familiares, distribuídos em 17 comunidades rurais do município, cujas perguntas envolveram questões sobre a terra, o trabalho e as relações com o mercado. Concluiu-se que a agricultura familiar de Uruçuí manifestava uma grave crise social marcada, sobretudo, por parcos rendimentos financeiros e dificuldades de acesso às linhas de crédito rurais, o que comprometia a produção familiar, repercutindo na economia de aprovisionamento e na pluriatividade.

Palavras-chave: Agricultura familiar; Agronegócio; Cerrado Piauiense; Pluriatividade.

\begin{abstract}
This article aims to examine how family farmers in Uruçuí, Piauí, characterized by a heritage of traditional knowledge and practices that adjust to modernity, build their economic reproduction strategies to meet their production and consumption needs, considering that the municipality consolidates itself in the activities of globalized agribusiness, which has caused uncertainties about the future of family farm work. The analysis is based on the ethnographic method, through systemic observations and application of semi-structured interviews with 254 family farmers, distributed in 17 rural communities in the municipality. The questions involved the use of land, work and relations with the market. It was concluded that family farming in Uruçuí manifested a serious social crisis characterized, above all, by meager financial income and difficulties in accessing rural credit lines, prejudicing the family production, impacting the supply economy and pluriactivity.
\end{abstract}

Keywords: Family Farming; Agribusiness; Cerrado Piauiense; Pluriactivity. 


\begin{abstract}
Resumen
Este artículo pretende examinar cómo los agricultores familiares de Uruçuí, Piauí, marcados por una herencia de conocimientos y prácticas tradicionales que se ajustan a la modernidad, construyen sus estrategias de reproducción económica para satisfacer sus necesidades de producción y consumo, debido a la consolidación del agronegocio globalizado en el municipio, lo que ha causado incertidumbres sobre el futuro del trabajo agrícola familiar. El análisis se basa en el método etnográfico, por medio de observaciones sistémicas y de la aplicación de entrevistas semiestructuradas a 254 agricultores familiares, distribuidos en 17 comunidades rurales del municipio, cuyas preguntas se referían a cuestiones sobre la tierra, el trabajo y las relaciones con el mercado. Se concluyó que la agricultura familiar de Uruçuí manifestaba una grave crisis social marcada, sobre todo, por los escasos recursos financieros y las dificultades de acceso a las líneas de crédito rural, que comprometían la producción familiar, repercutiendo en la economía de provisión y en la pluriactividad.
\end{abstract}

Palabras clave: Agricultura familiar; Agroindustria; Cerrado de Piauí; Pluriactividad.

\title{
1. Introdução
}

Muitas teses acadêmicas e estudos científicos e/ou técnicos já têm oferecido valiosa contribuição à renovação das concepções sobre a agricultura familiar. Nesse contexto, destacam-se trabalhos sobre a importância das atividades não agrícolas no espaço rural, as pluriatividades, o part-time farming, as novas ruralidades, as multifuncionalidades, entre outros. Mas, há ainda, todavia, muito o que debater, haja vista a polissemia dos discursos e a complexidade e heterogeneidade de situações (social, econômica e cultural) com as quais convivem os agricultores familiares nos distintos países e nas diversas regiões do Brasil.

Os argumentos de que a agricultura familiar denota uma atividade de baixa multifuncionalidade são desmentidos por Graeub et al. (2016) ao constatarem que esta responde por cerca de 53\% do montante da produção agrícola global e das propriedades rurais e por $98 \%$ das lavouras temporárias ou não, o que evidencia sua importância no contexto da segurança alimentar e a necessidade de maior atenção nas agendas políticas dos países e dos organismos internacionais.

Ainda no prisma da realidade concreta da agricultura familiar, particularmente no Brasil, Sabourin (2009) acrescenta que a criação do Programa Nacional de Fortalecimento da Agricultura Familiar (Pronaf), por meio do Decreto 1.946, de 28 de junho de 1996, e a criação de departamentos governamentais voltados para a agricultura familiar, como o Ministério do Desenvolvimento Agrário (MDA), a partir de 1999, simbolizaram conquistas para o trabalhador rural, haja vista o poder de lobby da agricultura empresarial no âmbito do Congresso Nacional, personificado nas ações da chamada Bancada Ruralista (composta por parlamentares do setor agropecuário e/ou defensores do agronegócio).

Mas, apesar da importância do Pronaf na sustentabilidade da agricultura familiar, Sabourin (2019, p. 146) critica o fato do Programa ter se consubstanciou em uma política limitada e seletiva, na medida em que o crédito disponibilizado para reestruturação das unidades produtivas familiares "beneficiou principalmente os agricultores mais abastados em capital e articulados com a rede bancária, essencialmente nos estados do Sul do Brasil".

Neste artigo reconhece-se o Pronaf como um mecanismo das políticas públicas que visa propor caminhos para a dinamização da economia agrícola familiar, sendo, portanto, uma estratégia inovadora para o alcance do desenvolvimento local em milhares de municípios do país. Mesmo apresentando limites quanto a capacidade de investimentos e assessoria técnica às demandas e necessidades da totalidade de agricultores familiares, principalmente nas regiões Nordeste e Norte do Brasil, o Pronaf se mostra potencial às perspectivas de desenvolvimento rural mais amplo, personificando avanços nas políticas governamentais voltadas à economia de base familiar.

No arcabouço teórico contemporâneo de estudos agrários e rurais, registra-se posições e oposições sobre a definição de agricultura familiar no Brasil. A definição para fins de políticas públicas tem caráter operacional do Estado, institucionalizado na política do Pronaf, por meio da Lei $n^{\circ} 11.236$, de 24 de julho de 2006, estabelecendo as diretrizes para a formulação de uma política nacional de fortalecimento da agricultura familiar e dos empreendimentos familiares rurais, passando a reconhecer a importância da atividade no desenvolvimento do país. As críticas à concepção governamental de 
agricultura familiar se embasam, entre outras coisas, na assertiva de que o desenvolvimento desigual do campo brasileiro, cujas políticas públicas estatais favoreceram sobremaneira o latifúndio, configurou uma modernização dolorosa para a pequena propriedade familiar.

Para Silva, Monteiro e Barbosa (2016) e Silva (2021), a agricultura familiar é uma instituição social cuja finalidade reside na reprodução da família, e que, embora o agricultor familiar manifeste novos hábitos de produção e consumo, não rejeita a sua raiz camponesa. Essa análise se harmoniza à concepção de Wanderley (2009), de que a agricultura familiar é um termo genérico que incorpora múltiplas situações particulares, das quais o campesinato se manifesta como referência à história e à cultura dessa categoria social. E que apesar do processo de modernização da sociedade, o agricultor familiar, e nesse caso o do cerrado piauiense, mantém uma ordem tradicional, que lhe define frente os padrões globais de produção e consumo.

Sendo assim, concorda-se com a concepção de Wanderley (2009), de que o agricultor familiar se mostra resiliente às transformações impostas pelo capital na agricultura, posto que tendo que se adaptar aos imperativos da agricultura moderna, comandada pelo agronegócio, ele guarda ainda muito dos seus traços e virtudes camponeses.

No movimento de difusão do agronegócio nos biomas Amazônia e Cerrado, expresso na chamada expansão da fronteira agrícola, a modernização da estrutura produtiva dos municípios vem acompanhada de mudanças sociais, econômicas, ambientais e culturais que atingem as paisagens, o cotidiano, os modos de vida, as relações de trabalho e o uso da terra. Por conta disso, Sawyer (2008) reclama que essa modernização tem resultado num quadro de impactos socioeconômicos e ecossistêmicos que interfere na vida das comunidades rurais e na resiliência do patrimônio natural, cuja convergência de passivos aponta para desigualdades na posse da terra, distribuição da renda e danos à biodiversidade, solos, recursos hídricos e atmosfera.

Esse movimento de reprodução do capital via ocupação de novas terras no Brasil, que inclui o Piauí, é um fenômeno recente da história agrária e agrícola do país, que tem provocado várias situações que marcam os territórios, como a manutenção da estrutura fundiária concentrada, processos de seletividade espacial, concentração da renda e da riqueza, impactos ambientais que atingem as florestas e a qualidade dos recursos hídricos e dos solos, processos de desterritorialização cultural das populações rurais e uma economia em escala derivada da produção agrícola e pecuária, principalmente commodities (Silva, Monteiro \& Barbosa, 2018; Rede Social de Justiça e Direitos Humanos, 2018).

Nos cerrados piauienses, a expansão da fronteira agrícola tem reorganizado a estrutura produtiva, reconfigurado o espaço e apresentado uma nova geografia rural comandada pelo agronegócio globalizado. Como exemplo axiomático de cidade vinculada às lógicas da territorialização do agronegócio no cerrado piauiense destaca-se Uruçuí, por ser município pioneiro em abrigar empresas do capital agrário, ofertar a infraestrutura necessária para a instalação de empreendimentos do agronegócio, por apresentar boas condições geoambientais para a produtividade da terra e um atrativo mercado imobiliário de terras (Silva, Monteiro \& Barbosa, 2020).

A configuração de Uruçuí como 'cidade do agronegócio' tem interferido no futuro da agricultura familiar. Conforme Silva (2021), as políticas estatais consentiram a permanência e o aprofundamento de um quadro de desigualdades sociais que ameaçam a continuidade da agricultura familiar em Uruçuí, haja vista que a ação do Estado viabilizou a manutenção das grandes propriedades rurais, repercutindo na expulsão de parcela significativa de agricultores familiares das terras de moradia e trabalho.

Em virtude da presença do agronegócio nos cerrados do sudoeste piauiense, externalizada pela agricultura empresarial, os agricultores familiares se sentem obrigados a redimensionarem as práticas econômicas e sociais de sobrevivência, embasados simplesmente no trabalho familiar ou como produto integrado ao agronegócio, o que suscita a necessidade de redefinição de suas identidades socioculturais no sistema agrícola familiar (Moraes, 2009).

Essa assertiva desperta para a análise das distintas possibilidades de continuidade da agricultura familiar, posto que 
para Silva e Hespanhol (2016), em razão dos dilemas vividos pela agricultura familiar, como as dificuldades econômicas (crédito, assistência técnica, inserção aos mercados, por exemplo), ela tem acionado diversas estratégias como forma de garantir sua reprodução socioeconômica.

Inclusive para Schneider (2003, p. 108, apud Marini \& Pieroni, 1987), essas estratégias são mediadas por situações objetivas, e sua racionalidade manifesta "o resultado das escolhas, opções e decisões dos indivíduos em relação à família e da família em relação aos indivíduos (...) essas estratégias ocorrem nos limites de determinados condicionantes sociais, culturais, econômicos e até mesmo espaciais, que exercem pressões sobre as unidades familiares". A partir dessa perspectiva, o autor defende as pluriatividades como estratégias de reprodução social e econômica protagonizadas pelo agricultor familiar, sendo um fenômeno da multiplicidade de formas de trabalho e renda das unidades agrícolas.

Essa característica do agricultor familiar em propor soluções para a manutenção do trabalho agrícola e o bem-estar da família tem raízes na matriz camponesa. Para Chayanov (1974), a performance das unidades agrícolas deriva do balanço trabalho/consumo, que a combinação dos fatores de produção, terra, mão de obra e capital, apresentam-se favoráveis para a satisfação das necessidades da família, desde que seja sistematizada organizadamente. E, caso ocorra desequilíbrios no uso dos meios de produção, a solução para a existência familiar se encontra na realização de atividades rurais não agrícolas, particularmente, artesanais e comerciais. Assim, constata que o ingresso do camponês nas atividades não-agrícolas consiste em uma estratégia de alocação da força de trabalho familiar em virtude das limitações da unidade produtiva agrícola.

Outra caracterização verossímil de estratégias de reprodução social e econômica do agricultor familiar é tematizada por Sahlins (1983), ao descrever a constituição de estratégias guiadas por uma economia de aprovisionamento, cuja finalidade da produção familiar estaria subordinada às relações parciais com o mercado. Nesse sentido, a lógica da produção não se baseava completamente no uso direto, para o consumo, senão para a troca, de modo a obter bens de que precisavam e não produziam. Portanto, registra o imperativo de uma economia direcionada para o mercado, que apesar de não visar o lucro, posto os limites da produção e da inexistência da propensão inerente ao trabalho contínuo.

As concepções de Chayanov (1974), Sahlins (1983), Schneider (2003), Moraes (2009) e Silva \& Hespanhol (2016) vão de encontro à análise de Redin (2012, p.158), de que as estratégias sociais e econômicas originárias do trabalho do agricultor familiar são fruto de "decisões tomadas em determinados contextos, influenciadas por diversos elementos no tempo e no espaço". Portanto, neste artigo, entende-se as estratégias socioeconômicas como meios, formas, objetos, ações e práticas capazes de proporcionar ou garantir a reprodução social (individual e coletiva) no conjunto da agricultura familiar. Além disso, infere-se que as estratégias de reprodução socioeconômica do agricultor familiar resultam, a priori, dos limites impostos pelo processo de desenvolvimento das forças produtivas.

Diante do exposto, questiona-se como a economia do trabalho agrícola familiar em Uruçuí tem resistido aos imperativos da expansão da fronteira agrícola liderada pelo agronegócio granífero? Questiona-se também quais as dinâmicas e dilemas vividos pelos agricultores familiares de Uruçuí inerentes para a continuidade do trabalho agrícola familiar? Ou seja, como se manifestam as estratégias praticadas pelos agricultores familiares de Uruçuí visando a garantia de sua reprodução socioeconômica? Nesse sentido, registra-se que este artigo pretende analisar a economia do trabalho agrícola familiar no cerrado piauiense, tendo Uruçuí como área de estudo. Assim, o artigo visa compreender as dinâmicas e os dilemas impostos à agricultura familiar em Uruçuí, outrossim a sua capacidade de resiliência perante a hegemonia do capital agrário e agroindustrial no município.

\section{Metodologia}

\subsection{Classificação da pesquisa e procedimentos para a coleta e análise dos dados}

Esta investigação socializa parte dos resultados de uma tese de doutorado defendida no ano de 2016, cujo objetivo 
pretendeu compreender as interferências da engenharia e da racionalidade da agronomia científica praticada pelo agronegócio granífero nos modos de vida dos agricultores familiares do cerrado piauiense.

A pesquisa se embasou na etnografia, que consiste em "um método da maiêutica social que permite ao informante ter um conhecimento de si mesmo, a possibilidade de conhecer o seu grupo social, a sociedade e sua cultura" (Mucchieli, 1996, p.63). Portanto, a etnografia apresenta-se como fundamental para o conhecimento dos imperativos econômicos, das tradições e das relações homem/natureza que se estabelecem no território Silva (2016). Com base no dito método, o estudo assentou-se na análise qualiquantitativa. Trata-se, portanto, de uma investigação descritiva/explicativa, no qual o pesquisador ao não controlar os eventos e as variáveis, busca descrever, interpretar e avaliar a complexidade de uma realidade, de processos e/ou fenômenos.

As coletas empíricas foram realizadas entre os meses de janeiro a junho de 2015, tempo suficientemente longo para o desenvolvimento de interpretações confiáveis e objetivas. Assim, a orientação, por meio do método etnográfico, possibilitou o estabelecimento de relações de confiança entre o pesquisador e os agricultores familiares, pois foram muitos os convites para 'passar a noite' (dormir nas comunidades), conhecer as roças, os lugares de farinhada, os criatórios e os canteiros com hortaliças. A gentileza e generosidade são virtudes dos agricultores familiares do cerrado piauiense, pois não faltou, dentre eles, quem oferecesse uma xícara de café, um pedaço de bolo de milho ou macaxeira, um convite para almoçar ou jantar, cujo cardápio era quase sempre composto por um pouco de farinha, feijão, arroz e, por vezes, acompanhado por uma criação ou caça. Também não faltaram, na frugalidade da vida rural, momentos descontraídos de trocas de ideias ou, como diziam os agricultores, 'de jogar conversa fora', cujos assuntos envolviam, inevitavelmente, enredos de política, economia e/ou futebol. Toda essa cordialidade dos agricultores contribuiu para superar a condição de estranhamento ou desconfiança à investigação.

A definição da amostra dos agricultores familiares elegeu as propriedades rurais cujas dimensões não ultrapassavam a quatro módulos fiscais, uma vez que para Silva (2016), esses imóveis rurais são reais representantes da situação socioeconômica da agricultura familiar em Uruçuí, como também denotam fatores de produção (terra, capital e trabalho). Ressalta-se que em Uruçuí, o módulo fiscal corresponde a 75 hectares.

Por meio do Programa Sample Size Calculator by Raosolft estabeleceu-se o erro amostral de 5\% e o nível de confiança de 95\% para o universo de 741 propriedades rurais com até quatro módulos fiscais cadastrados pelo Incra (2013), assim determinou-se a amostra de 254 agricultores familiares, os quais residiam nas comunidades rurais Flores, Santa Teresa, Graciosa, Lajeiro, Malhada da Areia, Mato Verde, Morrinhos, Pratinha, Pontes, Porto Velho, Sangue, Santo Antônio, Sucupira, Vão do Lourenço, Vereda do Mato, Tamboril e Tucuns. A escolha dessas comunidades se fundamentou na análise de Silva (2016), de que tais comunidades passam por intensos processos de desterritorialização decorrente da instalação do agronegócio.

Sustentado na etnografia, a coleta de dados empíricos utilizou ainda de observações sistemáticas por meio de histórias ou relatos de vida (Brioschi \& Trigo, 1987), isto é, do cotidiano dos 254 agricultores, sendo aplicadas entrevistas semiestruturadas orientadas por tópicos-guias (Triviños, 1987) a fim de coletar informações sobre a situação socioeconômica dos agricultores, o que incluiu saber sobre as estratégias de reprodução embasadas no uso da terra, nas práticas do artesanato, no destino da produção, na mão de obra utilizada nas roças e nas pluriatividades, e nas formas de financiamento da produção. Usou-se ainda de gravador de áudio e diário de campo para registrar o cotidiano da investigação.

Os dados quantitativos foram tratados por meio do programa eletrônico Statistical Package for the Social Sciences. Já a análise qualitativa dos discursos gravados se baseou na transcrição (Manzini, 2006) e leitura das falas, respeitando os depoimentos dos agricultores, pois para Orlandi (2000), essa técnica possibilita o entendimento de como um objeto produz sentidos e significados para e por sujeitos. A investigação foi aprovada pelo Comitê de Ética em Pesquisa da Universidade Federal do Piauí, por meio do Parecer Consubstanciado de Aprovação Ética, sob o número 1087335, o que garantiu o sigilo 
sobre as identidades dos informantes.

Inferiu-se que a aplicabilidade do método e procedimentos técnicos apresentados foi imprescindível para fornecer segurança às conclusões do estudo, na medida em que possibilitaram construir análises e interpretações sobre o fenômeno investigado, sem incorrer em distorções que colocasse em risco a representatividade dos resultados.

\section{2 Área de estudo}

Registra-se, em conformidade com IBGE (2021), que Uruçuí pertence à região sudoeste piauiense, apresenta área territorial de 8.413,016 km2, que se limita, ao Norte, com o estado do Maranhão e o município piauiense de Antônio Almeida, ao Leste, Landri Sales, Sebastião Leal e Manoel Emídio, ao Sul, Alvorado do Gurgueia e Palmeira do Piauí e, a Oeste, Baixa Grande do Ribeiro, Ribeiro Gonçalves e o estado do Maranhão (Figura 1).

Figura 1: Mapa de localização espacial de Uruçuí/PI.

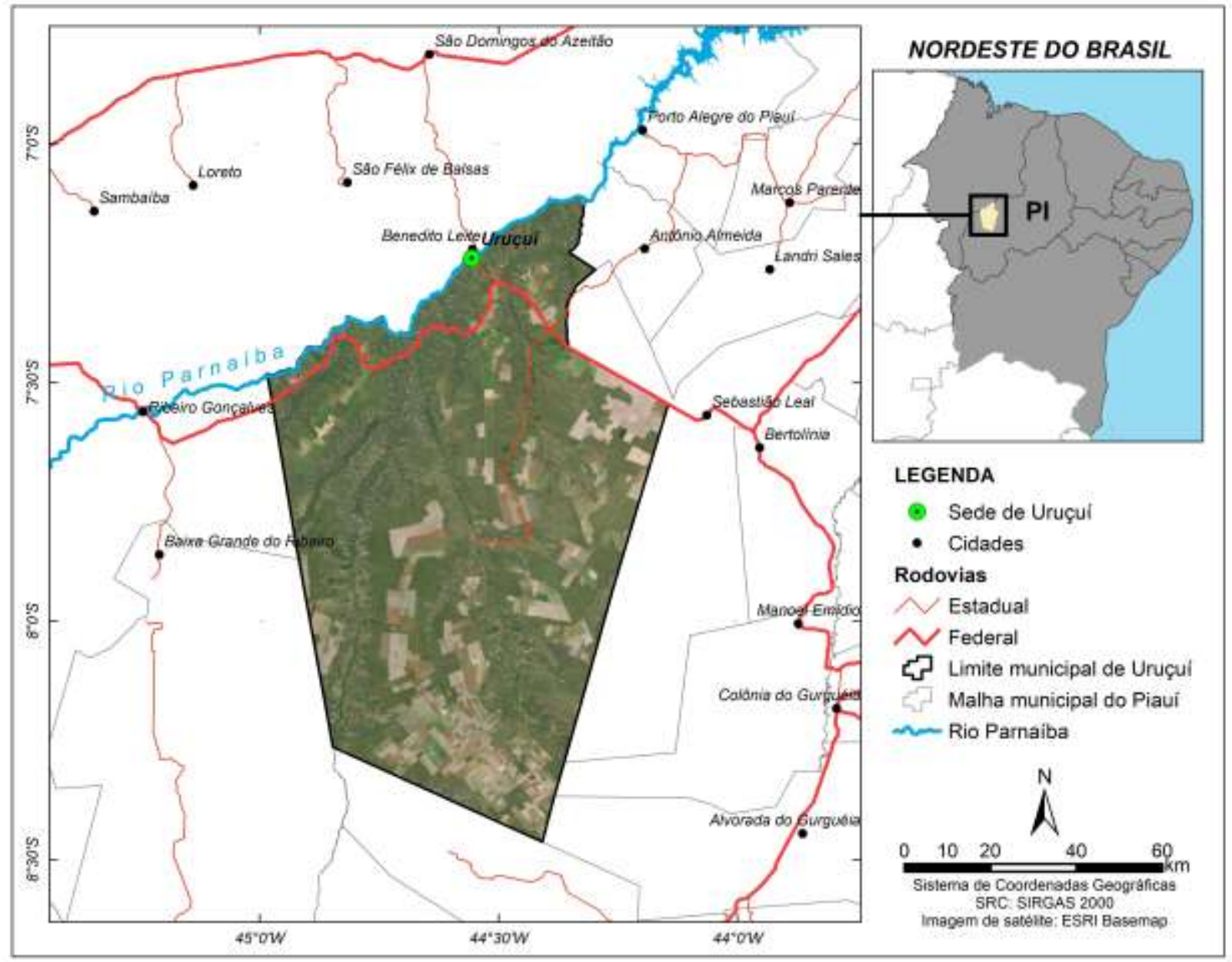

Fonte: Morais (2021).

Outrossim, Uruçuí apresenta uma população estimada, em 2021, de 21.746 habitantes, destes, 77,0\% residem na zona urbana e 23,0\% na zona rural. Ademais, o município contava com um Índice de Desenvolvimento Humano Municipal (IDHM) de 0,631 (IBGE, 2010, 2021).

Uruçuí foi fundado em 07 de setembro de 1902, suas terras foram desmembradas do município de Bertolínia que dista aproximadamente 397 km de Teresina, capital do estado do Piauí. A instalação de Uruçuí ocorreu durante a chamada nova reorganização político-administrativa do espaço piauiense, período marcado pelas tramas políticas da Primeira República 
(1989-1930), em âmbito nacional, e pela criação de novos municípios, navegação do rio Parnaíba e desenvolvimento da economia do extrativismo vegetal, sobretudo, maniçoba, carnaúba e babaçu, em nível estadual (Assis Silva, 2016; Silva, 2021).

Em Uruçuí, o agronegócio se instalou seguindo as mesmas características da ocupação de outras cidades apropriadas, especificamente favorecido pela política estadual (incentivos fiscais, estímulos à pesquisa científica, infraestrutura, terras a valores ditos "simbólicos", etc.) e pelos aspectos geoambientais considerados favoráveis como topografia, clima, solo e hidrografia. Todavia, em contrapartida, a agricultura familiar foi excluída dos planos estatais, uma vez que o agronegócio avança sob as terras de uso comum, causando incertezas sobre a continuidade dos modos de vida e das identidades territoriais (Silva, 2016).

Nesse sentido, faz-se possível enfatizar a opinião de Bernardes (2015, p.507) de que "fenômenos de abertura de novos espaços produtivos e de cooperação podem ser identificados, vinculados a novos potenciais, com suas múltiplas influências e condicionantes, bem como a fenômenos de fechamento de espaços tradicionais".

\section{Resultados e Discussão}

A pesquisa nas comunidades rurais indicou que do total do universo amostral de 254 agricultores, $81,5 \%$ eram originários de Uruçuí; 10,2\% eram oriundos de outros municípios piauienses; e 8,3\% eram dos estados da Bahia, Maranhão, Paraíba, Paraná e Pernambuco. Do total de nascidos em Uruçuí, 91,3\% eram da zona rural e 8,7\% da sede do município, o que possibilitou caracterizá-los como antigos habitantes do entorno rural, detentores de uma ancestralidade camponesa, uma vez que suas memórias sócio-históricas se harmonizavam com as observações de Moraes (2006), que por meio de estudos sobre as master narratives (narrativas mestras), concluiu que a população rural do sudoeste piauiense espelhava traços marcantes de campesinato, por reproduzirem seus modos de vida sob uma economia de pequena dinamização.

Outras características da agricultura familiar em Uruçuí se revelaram no baixo nível de escolaridade e na estrutura fundiária municipal. A defasagem educacional presenciada em Uruçuí apontou para um contexto de ineficiência das políticas governamentais voltadas para o sistema público de ensino. A situação fundiária estava marcada por incertezas quanto à posse $\mathrm{e}$ ao uso da terra, uma vez que era preponderante a quantidade de agricultores que não souberam informar o tamanho da propriedade a qual pertenciam, devido serem vulneráveis às pressões sobre a condição da propriedade da terra, como agregados, arrendatário e ocupantes, os quais em geral, historicamente habitavam o cerrado uruçuiense, onde o vínculo com a terra ocorria por relações de posse e de não-propriedade jurídica. Esse quadro se agrava com as migrações entre comunidades, em função do avanço do agronegócio nas chapadas. Esse condicionante confirmava o quadro de exclusão social a que os agricultores estavam expostos em Uruçuí. E confirmava os estudos do IBGE $(2020 ; 2021)$ quanto ao IDH de Uruçuí, um dos piores do Piauí.

Quanto ao perfil socioeconômico dos agricultores familiares, a pesquisa de campo demonstrou que dos 254 agricultores, 52,4\% tinham a atividade agrícola familiar como principal fonte de renda e alimentícia, 24,4\% dependiam do trabalho formal e 23,2\% eram aposentados, estes últimos convertiam parte do salário na produção agropecuária. Ressalta-se que do montante de agricultores inseridos no trabalho formal, 11,0\% eram das fazendas, 5,5\% do serviço público, 3,9\% da construção civil, $3,2 \%$ do comércio e $0,8 \%$ da agroindústria. De fato, entendeu-se que, por um lado, os 47,6\% dos agricultores que dependiam da renda vinda de fora da atividade agrícola apresentavam vulnerabilidade econômica para seguir no trabalho agrícola, o que colocava em risco e em questão o papel desempenhado pela economia agrícola familiar como difusora de multifuncionalidades. E que, por outro lado, essa configuração se adequou com a análise de Schneider (2003), de que as múltiplas atividades desempenhadas pelo agricultor familiar caracterizavam a dinâmica pluriativa, que o capacitava a construir caminhos de sobrevivência.

Diante dessa situação, inferiu-se que a emergência das pluriatividades como linha de fuga para fazer cumprir o 
atendimento das necessidades de produção e consumo dos agricultores denotava insegurança sobre o futuro da atividade em Uruçuí, seja porque as roças não garantiam um salário capaz de satisfazer as demandas das famílias, seja porque as possibilidades de inserção em atividades não agrícolas ou no agronegócio despertavam o interesse dos mais jovens. O agricultor familiar que nasceu e aprendeu a viver da produtividade da terra não migra para outras atividades por vontade, por gosto ou desejo, as restrições financeiras e o quadro de exclusão social são questões inerentes ao imperativo das pluriatividades no espaço rural de Uruçuí.

Além do mais, registrou-se que $81,5 \%$ dos trabalhadores contavam com a ajuda da família para o desenvolvimento da produção agrícola, enquanto 18,5\% desempenhavam as atividades da roça de forma individualizada. Esse cenário de preponderância do grupo doméstico na lavoura, associou-se com o inciso IV, do artigo $3^{\circ}$, da Lei 11.326, de 24 de julho de 2006 (Pronaf), a qual estabeleceu que o agricultor dirija seu estabelecimento ou empreendimento rural com a ajuda da família. Como também, se coadunou com a opinião de Chayanov (1974), de que a sobrevivência da pequena propriedade se orientava preponderantemente do cálculo elaborado pelo agricultor, entre a quantidade de consumo e o grau de exploração da força de trabalho. E por conta dos baixos rendimentos financeiros nas comunidades, sobressaia o trabalho familiar.

Assim, acrescenta-se que o papel da família na viabilidade da agricultura ficou evidenciado, ainda, quando se verificou que da totalidade da amostra, 60,2\% dos agricultores familiares não contratavam e 39,8\% contratavam serviços temporários de terceiros. Outrossim, notou-se que o grupo dominante organizava as tarefas da roça a partir da contribuição de parentes, distribuída entre 58,2\% de cônjuge e filhos, 37,9\% somente cônjuge e 3,9\% de outros membros, com diferentes níveis de parentesco, como tios, primos e avós, expressando, destarte, o que Wolf (1976) chamou de família extensa, devido agrupar um certo número de famílias nucleares, estas, por sua vez, consistem em agricultores cuja vivência e/ou artifício de segurança alimentar dependem das habilidades produtivas de cada membro do grupo. Por essa razão, reconheceu-se a importância desse tipo de estrutura social na segurança produtiva da agricultura familiar em Uruçuí, posto que a presença dos filhos era a certeza da continuidade do trabalho de base familiar.

Já para o grupo contratante, a vigência da roça se efetivava através da ajuda externa (a média foi de um trabalhador por família), onde a natureza do contrato temporário entre as partes se consumava por meio de acordo verbal, vinculando-se, portanto, aos valores tradicionais de ordem camponesa ressaltados por Sabourin (2009), como confiança, amizade, honra e respeito à palavra. Ademais, observou-se que o pagamento dos trabalhadores era em salário, cujo valor médio por um dia de trabalho era fixado em $\mathrm{R} \$ 41,08$. Salvo questões organizadas pela economia da região, entendeu-se que este valor era considerado baixo, dadas as condições de trabalho, pois na agricultura, só se contrata terceiros para trabalhos pesados que a família não dá conta.

Salienta-se que essa proposição se harmonizou com o inciso II, do artigo $4^{\circ}$, da Lei 4.504, de 1964 (Estatuto da Terra), a qual estabeleceu o conceito de propriedade familiar e que foi utilizada na instituição do Pronaf, definida como uma unidade de produção doméstica explorada direta e pessoalmente pelo agricultor e sua família e, eventualmente, absorve o trabalho de terceiros.

Porém, devido à territorialização do capital, provocada pelo agronegócio no cerrado uruçuiense, entendeu-se que o contexto de contratação de diaristas agrícolas expressou um processo de reconversão das prestações de ajuda mútua entre os comunitários, haja vista que historicamente a prática regular de mutirões era fundamentada nas regras de compartilhamento, solidariedade e reciprocidade. Essa particularidade foi narrada por um agricultor familiar de 63 anos.

Hoje, no meu modo de ver, a roça tá ficando pra traz, porque o custo tá muito alto. Hoje, o que o trabalhador produz durante o dia não cobre o valor da diária que é $\mathrm{R} \$ 40,00$, aí, por aí tá ficando mais curto o serviço, e dois braços sozinho (sic) fica meio cansado. Quando antigamente se fazia mutirão, tinha cinco, seis lavrador (sic), eles se reuniam e faziam o mutirão, faziam uma roça juntos (Informação verbal). 
A narrativa de história oral do agricultor familiar revela os dilemas impostos à pequena propriedade, esta, historicamente, não recebeu, e não continua recebendo, o mesmo tratamento disponibilizado às médias e grandes propriedades ou latifúndios por parte das políticas governamentais. É fundamental recordar que a modernização do campo brasileiro foi um processo desigual e combinado, arquitetado conscientemente pelos defensores do agronegócio para a reprodução do latifúndio, esse processo se atualiza no processo de expansão da fronteira agrícola no Piauí, em que a pobreza e a exclusão do agricultor familiar mostra-se uma realidade perversa e contraditória da história agrária do Brasil. Essa situação confirmou a concepção de Silva (2016), de que a difusão do agronegócio em Uruçuí ocorre diametralmente às políticas de consolidação da agricultura familiar.

Além disso, a fala do agricultor se adequou ao entendimento de Sabourin (2009, p.69), de que as novas relações de ajuda mútua são personificadas na monetarização, fato que tornou mais rara a regularização dos mutirões, pois "quando tais práticas são dominadas pela lógica da troca elas não garantem mais a atualização das estruturas de reciprocidade que mantêm a produção dos valores humanos éticos".

De fato, devido às insatisfatórias condições socioeconômicas das comunidades e o pouco alcance das políticas públicas para a agricultura familiar, os chefes de família eram obrigados a ocupar temporariamente os postos de trabalho nas fazendas, no qual se sobressaiam as funções menos valorizadas e baixamente remuneradas, como os serviços gerais, o que resultou em impactos imediatos no cotidiano das localidades, particularmente nas relações de reciprocidade e no uso da terra.

Notou-se, em geral, que os agricultores familiares de Uruçuí eram essencialmente dedicados ao cultivo da terra e à criação de animais, posto que 72,4\% estavam nessa condição a mais de 25 anos, ou seja, já exploravam o patrimônio natural muito antes da chegada do agronegócio. Desse total, 52,4\% trabalhavam com a agropecuária a mais de 35 anos, 10,6\% entre 30 a menos de 35 anos e 9,4\% de 25 a menos de 35 anos. Essa contextura enfatizou a relevância da tradicionalidade, por conferir uma realidade concreta em que as peculiaridades históricas, sociais e culturais organizavam o saber-fazer na roça. Sublinha-se que esse panorama se associou à análise de Bourdieu $(1988,1991)$, de que a organização e o saber são características intrínsecas do habitus, intimamente ligado a raiz camponesa, adquirido ao longo do tempo, por meio de uma dinâmica própria e de forma particular.

Em função dessa conjuntura, inferiu-se alicerçado na pesquisa de campo, que arroz (Oryza sativa L.), milho (Zea mays L.), mandioca (Manihot esculenta Crantz), feijão (Phasealus vulgaris L.) e fava (Vicia faba L.), listavam como os principais produtos da dieta alimentar das famílias. Outrossim, constatou-se que em função do local de cultivo dos ditos legumes, as populações os reconheciam, genericamente, como culturas de sequeiro e vazante ou brejo (baixão). Sendo que a primeira se caracterizava por lavouras cultivadas em áreas de chapadas, e a segunda, por produtos plantados em terrenos baixos, onde as temperaturas eram amenas (úmidas) e os solos alagadiços e/ou constituídos de ilhas e/ou de terras marginais fertilizadas pelas cheias de um rio, como o Uruçuí Preto. Nessa perspectiva, identificou-se o predomínio dos plantios nos baixões com 58,7\%; enquanto nas chapadas foi de 41,3\%, o qual decorreu do processo de ocupação dos platôs pelos empreendimentos graníferos do agronegócio, o que provocou o encurralamento dos agricultores familiares nos baixões ou os obrigou a migrarem para as cidades, como também, devido às condições naturais.

Acerca do destino da produção agrícola, a pesquisa empírica assegurou que 91,3\% dos agricultores não comercializavam as lavouras, pois a lógica para a produtividade do legume se pautava na subsistência da família. E para 8,7\% dos familiares, a oferta da safra ao mercado ocorria de forma parcial, o que caracterizou a economia de aprovisionamento. Essa configuração confirmou as argumentações de Martins (2012), de que sem embargo as determinações de mercado não estão imediatamente presentes no processo de trabalho do agricultor familiar, uma vez que ele não é imune às relações da sociedade capitalista. Então, o agricultor era obrigado a estabelecer vínculo com o dinheiro, pois sua sobrevivência dependeria residualmente das articulações e das influências que manteria com o mercado e o capital. 
Adenda-se que por meio da investigação, verificou-se que 72,5\% dos agricultores destinavam os rebanhos, preponderantemente, para o aprovisionamento, 23,2\% exclusivamente para o autoconsumo e 4,3\% não criavam. E que, estrategicamente, combinavam os diferentes criatórios, com fins de enriquecer o cardápio familiar e atender ao mercado local.

Como também, percebeu-se que $100 \%$ dos agricultores familiares não estavam preocupados em obter lucro com a comercialização do rebanho, senão adquirir mercadorias que precisavam e não produziam, principalmente as industrializadas. Essa contextura associou-se à análise de Sahlins (1979), de que a economia de aprovisionamento se sustenta na possibilidade de ampliação do suprimento das necessidades dos membros da família. E que em virtude de os agricultores não consumirem integralmente a produção, mantinham relações estreitas com o mercado, com vistas a assegurarem bens urgentes. Essa estratégia de reprodução socioeconômica de origem camponesa além de assegurar uma complementação da renda, revelou que agricultor familiar era um ator social num mundo em constante transformação, pois usufruía da modernidade como estratégia de reprodução social.

Observou-se que a comercialização do excedente era realizada em múltiplos lugares, 59,1\% somente na sede do município, $27,3 \%$ na sede do município e na própria comunidade a qual pertenciam, 9,1\% na comunidade de origem e 4,5\% outras comunidades. Todavia, inferiu-se, alicerçado em Lênin (1982), que essa dependência ao mercado revelou o avanço do capital na agricultura, ao controlar a produção dos produtores isolados e obrigá-los a levarem em conta as demandas da evolução da sociedade.

Prosseguindo a análise da estrutura econômica dos agricultores familiares, identificou-se que 68,5\% não confeccionavam objetos artesanais e 31,5\% desenvolviam essa atividade, consorciada com a atividade agrícola. Sendo que, desse montante, 92,9\% fabricavam os utensílios, como uma forma de preservarem os laços culturais, ou seja, de rememorarem a raiz camponesa e 7,1\% construíam os bens, motivados pela exigência de complementarem a renda. Porém, ressalta-se que a venda não consistia em cálculo guiado pela natureza capitalista, mas na certeza de assegurar a continuidade da unidade de produção doméstica.

Constatou-se que os produtos artesanais se distinguiam por 7,9\% abanos, $5,1 \%$ jacás, $4,3 \%$ coifos, $2,7 \%$ cestos, $2,0 \%$ tapitis, 2,0\% tarrafas de pesca, 1,6\% vassouras, 0,8\% esteira e cocheira, respectivamente, e 6,7\% de outros utensílios (peneiras, mesas, cadeiras, canteiros, cercas, paióis, chiqueiros, etc.). Registra-se que esses artefatos incrementavam o cotidiano das famílias nas terras de morada e de trabalho, simbolizando estilos de vida, costumes, saberes, arranjos técnicos e, ao mesmo tempo, ancestralidade, por isso eram incorporados nas práticas diárias, principalmente no preparo da alimentação, na estocagem da safra, no transporte de mercadorias, na farinhada, na piscicultura, no plantio, na colheita, enfim, nas diversas atividades desenvolvidas pelo trabalho social.

Destaca-se também, que os produtos artesanais eram provenientes do extrativismo vegetal regional (exceto a tarrafa de pesca), em especial das palmeiras do buriti (Mauritia flexuosa L. F.), carnaúba (Copernicia prunifera (Mill.) H. E. Moore), babaçu (Attalea speciosa Mart. ex Spreng) e tucum (Astrocaryum vulgare Mart.) e de outras espécies da flora como o tamburil (Enterolobium contortisiliquum (Vell.) Morong), o açoita-cavalo (Luchea divaricata Mart.), o jatobá (Hymenaea stignocarpa Mart. ex Hayne), o cedro (Cedrela odorata L.) e o pequi (Caryocar brasiliense Cambess). Tal interação homem/natureza se concatenou com a explicação de Leff (2009), de que as capacidades adaptativas e criativas dos povos de comunidades rurais derivam de séculos de experiências e coevolução de práticas tradicionais com as transformações do meio ambiente. Portanto, esclarece que o saber tecnológico autóctone articula a experiência propriamente técnica com toda a cosmovisão que reúne, num sistema holístico, processos de significação em que se contextualizam percepções, conhecimentos e estratégias inseridos em contextos geográficos, ecológicos, sociais, econômicos e culturais específicos.

Além disso, constatou-se a plenitude dos mais velhos em relação ao manejo sobre a seleção de espécies vegetais e sobre a particularidade de técnicas tradicionais associadas à confecção dos objetos, conforme ilustra a Figura 2. 
Figura 2: Agricultor familiar confeccionando coifo, comunidade Vão do Lourenço, Uruçuí/PI.

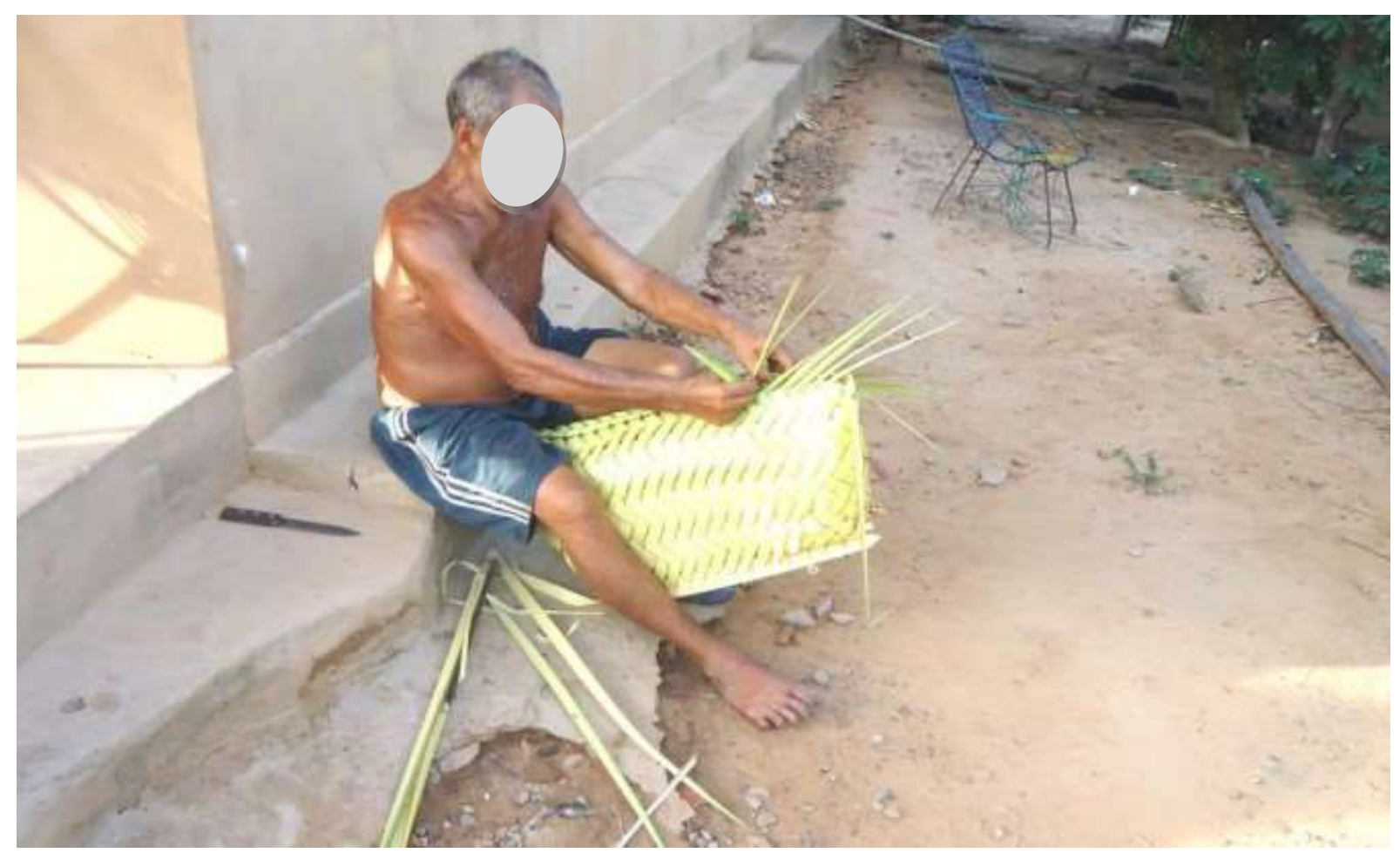

Fonte: Silva (2016).

Desse modo, inferiu-se que por um lado, o elevado índice de não artesãos, 68,5\%, evidenciou mudança social induzida pela imposição de novas posturas quanto à satisfação das necessidades básicas, devido ao processo de globalização da economia, bem como do processo de expansão da fronteira agrícola em Uruçuí, que repercutiu na entrada de produtos industrializados nas residências e nas roças. E, por outro lado, a permanência de artesãos se harmonizou com a visão de Chayanov (1974), de que a reprodução do artesanato na pequena propriedade manifestava uma estratégia campesina cujo único raciocínio se fundamentava no compromisso de garantir o equilíbrio entre consumo e força de trabalho.

A pesquisa de campo também apontou, a importância dos auxílios governamentais, como aposentadorias, pensões e Bolsa Família, do trabalho formal, das diárias e do comércio para a manutenção das famílias, por configurarem como as principais fontes de renda mensal. Assim, observou-se que do total do universo amostral de 254 agricultores, $47,0 \%$ contavam com auxílios governamentais como complemento da renda mensal familiar, 26,0\% com diárias, 24,0\% com trabalho formal e 3,0\% com comércio (sobretudo bodegas, bares e restaurantes).

Do montante que recebiam auxílios governamentais, 23,2\% eram aposentados, 22,8\% beneficiários do Programa Bolsa Família e 0,4\% pensionistas. Esse cenário expressou que a reprodução da pequena propriedade, em Uruçuí, era mantida preponderantemente por fontes de renda não agrícolas, inclusive oriundas de postos de trabalho no agronegócio, o que contrariou o inciso III, do artigo $3^{\circ}$, da Lei $n^{\circ} 11.326$, de 2006, que o agricultor familiar tenha renda econômica basicamente do seu estabelecimento.

Nessas circunstâncias, destaca-se que a análise da venda de produtos agropecuários e artesanais, como também do recebimento mensal de auxílios governamentais, do emprego formal, das diárias e do comércio não agrícola, como fonte de renda principal, revelou que do total dos chefes de família, 46,0\% percebiam de um a menos de dois salários mínimos mensais, 33,5\% menos de um salário mínimo, 20,1\% de dois a menos de três salários mínimos e 0,4\% superior a três salários mínimos. Essa configuração de reduzida capitalização dos trabalhadores suscitou a necessidade de analisar a aquisição de linhas de crédito bancárias entre as famílias, para a realização da produção agropecuária 2014/2015 (Figura 3). 
Figura 3: Crédito bancário para a produção agropecuária na safra 2014/2015, em Uruçuí/PI.

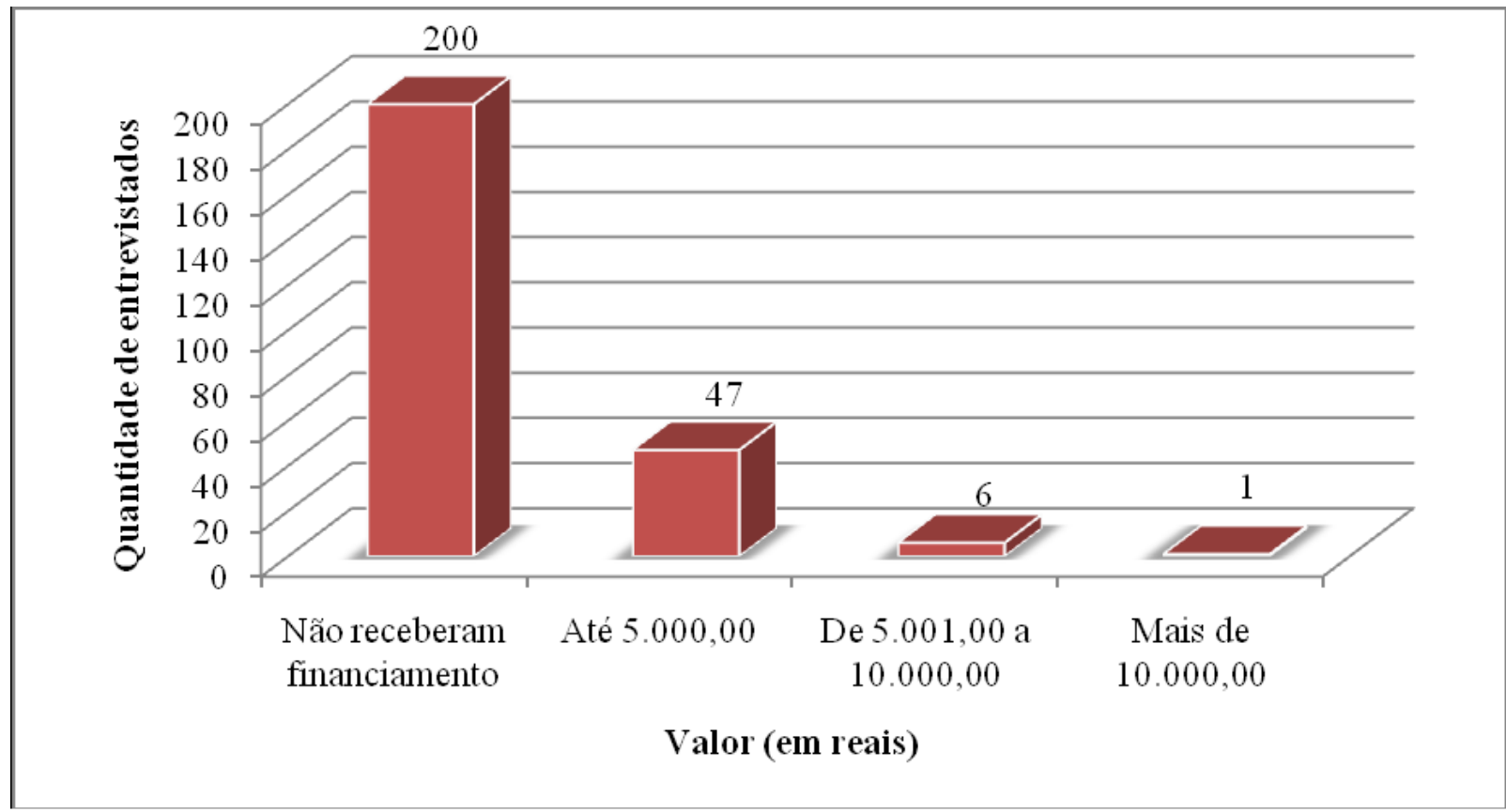

Fonte: Silva (2016).

Com base na Figura 3, percebeu-se que 78,7\% dos trabalhadores não receberam investimentos para custear a estruturação da produção agropecuária 2014/2015, enquanto 21,3\% recorreram aos créditos bancários. Os ditos financiamentos contemplaram $18,5 \%, 2,4 \%$ e $0,4 \%$ das famílias com valores que atingiam até $\mathrm{R} \$ 5.000,00$, que variavam de $\mathrm{R} \$ 5.001,00$ a $\mathrm{R} \$$ 10.000,00 e que ultrapassavam $\mathrm{R} \$ 10.000,00$, respectivamente. Outrossim, identificou-se que a totalidade dos recursos financiados era proveniente de linhas de crédito do Pronaf, concedidas via Banco do Nordeste do Brasil (82,7\%) e Banco do Brasil (17,3\%).

Verificou-se ainda, que a liberação do capital era condicionada a avaliação pelas agências bancárias, da posse da terra ou um aval do dono da propriedade, o qual confirmava a situação fundiária dos trabalhadores (assentados, agregados, arrendatários e ocupantes), de um projeto descriminando as intenções produtivas propostas, e de outros elementos econômicos que cercavam a situação financeira dos agricultores (saldos médios, aplicações, cartões de crédito). Assentado nesse panorama, compreendeu-se que tais condições excluíam muitos agricultores do acesso aos recursos, o que revelou que a problemática da realidade fundiária em Uruçuí, se consubstanciava também em grave problema social.

Nesse sentido, assinala-se que esse cenário de seletividade social para a distribuição dos financiamentos públicos, estava consoante com as críticas formuladas por Wanderley (2003), Tonneau, Aquino \& Teixeira (2005a, 2005b), e Sabourin (2009), sobre os contrapontos do Pronaf, devido, por um lado, legitimar socialmente, economicamente, culturalmente e ambientalmente a agricultura familiar, mas por outro lado, não promove, de maneira explícita, a implementação de mercados locais de proximidade ou de cadeias produtivas entre os agricultores e os consumidores. Por isso, reconhecem que os parâmetros políticos do Programa se sustentam na definição de agricultor moderno, ou seja, na concepção de agricultura empresarial, o que reforça a opção produtivista e setorial.

A pesquisa empírica também demonstrou, que embora fosse concedido o crédito bancário para os trabalhadores, isso não lhes assegurava a eficiência produtiva das roças, pois em virtude das incertezas do acesso à orientação técnica institucional, os agricultores manifestavam descontentamentos sobre a estrutura dos financiamentos, como está relatado na narrativa familiar. 
Eu fiz ele [Pronaf] uma vez e isso foi o que acabou com nós aqui no assentamento, porque foi plantado tudo direitinho, mas aí quando foi feito o Pronaf [...] não, não tem que ter um técnico? Aí, botaram uma firma aqui, gente daqui mesmo, a Emater. Aí, essas coisas foi (sic) plantado, todo mundo plantou, mas daquele jeito véio (sic) que a gente sabia, a preferência [vantagem] foi que a terra foi aradada, porque ele [extensionista] nem pra regular uma plantadeira pra plantar arroz; outra assistência de jeito nenhum. Aí, ninguém foi pra frente. [...] Aí, naquela época (2004), as terras tavam (sic) tudo aradada, o mato era pouco, não tava (sic) encapoeirado, não precisava tirar com a enxada, aí deu bom, deu muito arroz. A Emater só fez ganhar o dinheiro. Cada um [assentado] recebeu R \$15.000,00 [...] Aí, foi feito o projeto pra porco, pra gado, galinha, cajuína, ovelha, tudo cuidado mesmo pela gente. [...] Tudo foi plantado de qualquer jeito porque na máquina você tem saber a quantidade de caroços que cai por metro, e aqui, ninguém sabia regular uma máquina dessas, e a quantidade caroços, sabia que o jeito era aquele. Aí, tinha vez que o arroz nascia quatro, cinco pés enrrabados (sic) no monte, aí, por aí, começou o desmantelo. Aí, a metade pagou o Pronaf e outros não pagou (sic), porque não tinha como (Informação verbal).

Através desse depoimento, apreendeu-se que em Uruçuí, os horizontes de o Pronaf potencializar equitativamente o desenvolvimento da agricultura familiar, eram reduzidos, em consequência do quadro de inadimplência e/ou endividamento dos trabalhadores junto às agências bancárias, os obstáculos enfrentados para o custeio das lavouras e dos criatórios, e as insatisfações com a orientação técnica, as quais se coadunaram à análise de Grisa, Wez Júnior \& Buchweitz (2014, p.342), de que não raro, a extensão rural e a assistência técnica "apresentam dificuldades ou não estão preparadas para trabalhar com os segmentos menos capitalizados ou com projetos não convencionais, prevalecendo interpretações setoriais e produtivistas sobre o rural e a agricultura familiar".

Mas, apesar das rugosidades (imperfeições) apresentadas pelo Pronaf, reconhece-se sua importância no universo da agricultura familiar, vendo-o como um mecanismo das políticas públicas capaz de propor caminhos para a dinamização do desenvolvimento local em milhares de municípios do país. Mesmo apresentando limites quanto a capacidade de investimentos e assessoria técnica aos agricultores familiares de Uruçuí, o Pronaf é uma conquista dos movimentos sociais do campo, que precisa de redefinições visando a qualidade do Programa e a dignidade do agricultor familiar.

\section{Considerações Finais}

Este estudo descritivo e explicativo pretendeu contribuir para ampliar a reflexão e discussão sobre os contrapontos da consolidação do agronegócio, especialmente os que envolvem os processos de resiliência da agricultura familiar vis à vis à globalização da economia agrícola. O que ficou claro a partir dos dados analisados é que as estratégias de reprodução socioeconômica da agricultura familiar de Uruçuí são desafiadoras.

O território que se origina ou se redefine dessa configuração traz consigo distintos processos do desenvolvimento desigual no cerrado, onde as contradições se evidenciavam na realidade econômica dos trabalhadores familiares, caracterizada por baixos rendimentos monetários, diminuição de atividades artesanais e emergência de programas sociais de transferência de renda e a aposentadoria rural.

Em função desse cenário, ganhava destaque a produção que visava o aprovisionamento, calcada em saberes e práticas tradicionais, cuja força de trabalho era basicamente composta pelo grupo doméstico e, por vezes, pelo contrato em diária. Ademais, os agricultores eram pluriativos, na medida em que se ocupavam de outras atividades, como forma de complementarem a renda mensal e, por sua vez, não comprometer a continuidade da produção agropecuária, já que os parcos investimentos ofertados pelas instituições bancárias, a seletividade, as restrições e as limitações dos financiamentos não satisfaziam o progresso das suas propriedades rurais.

No entanto, entendeu-se a emergência das pluriatividades como linha de fuga que visava o atendimento das necessidades de produção e consumo dos agricultores, seja porque as roças não garantiam um rendimento financeiro capaz de satisfazer as demandas das famílias, seja porque as possibilidades de inserção em atividades não agrícolas ou no agronegócio despertavam o interesse dos mais jovens. 
Apesar dos recentes avanços das políticas públicas voltadas para o fortalecimento da agricultura familiar, como a institucionalização do Pronaf, a atividade padece de incentivos e ações efetivas que impliquem em estratégias e oportunidades de desenvolvimento inclusivo, democratizante, capaz de potencializar o empoderamento das comunidades rurais, suas competências, heterogeneidades, dinâmicas, qualidades e complexidade das suas funções.

Sendo assim, realça-se a urgência da introdução de ações e intervenções efetivas para a emancipação da agricultura familiar, cabendo às políticas públicas a atuação de reverter a problemática situação socioeconômica nas comunidades, e ao mesmo tempo, potencializar a organização das pequenas propriedades.

Em síntese, na medida em que o Estado assumiu um papel atuante na difusão do agronegócio em Uruçuí, e em contrapartida, diminuiu a participação na garantia dos bens coletivos, esses bens deixaram de ser acessíveis para a maioria dos agricultores familiares.

Portanto, por entender a questão como um assunto público, confere-se que o Estado deve reconhecer as reivindicações familiares, assentadas em investimentos e/ou dispositivos que propiciem a modernização das roças, a reestruturação das instituições de assistência técnica, a desburocratização do acesso ao crédito rural, a difusão do cooperativismo para fortalecer o capital social nas comunidades, melhorias na infraestrutura (principalmente logística de transportes e o saneamento básico), a regularização da posse da terra e a dinamização do mercado consumidor regional para os produtos agropecuários e artesanais.

Ressalta-se que o método etnográfico foi fundamental para a aferição dos problemas e para a interação com os sujeitos, na medida em que possibilitou reduzir as imprecisões no estudo crítico do objeto investigado, o que assegurou uma análise inexorável das informações, interpretações e afirmações sobre a realidade em questão.

Essa pesquisa não esgota as discussões sobre as complexidades provocadas pela expansão da fronteira agrícola no cerrado piauiense, já que é um movimento que alcança seu limite via expansão de novas fronteiras (Fritz et al., 2015), o que sugere a necessidade de pesquisas futuras que possam contribuir para o entendimento dos processos de resistência e resiliência da pequena propriedade em um campo de forças comandadas pelo agronegócio e orquestrado pelo Estado, este definiu sua posição: a serviço do capital.

\section{Referências}

Assis Silva, B. G. (2016). Economia: elemento norteador para a formação territorial do Piauí. Façanha, A. C. \& Cunha, M. A. (Orgs.) Piauí, desenvolvimento territorial escalas de abordagem. Teresina: Edufpi, 25-36.

Bernardes, J. A. (2009). Fronteiras da agricultura moderna no cerrado Norte/Nordeste: descontinuidades e permanências. In: Bernardes, J. A. \& Brandão Filho, J. B. (Orgs.). A territorialidade do capital: geografias da soja II. Arquimedes Edições, pp.13-39.

Bernardes, J. A. (2015). Novas fronteiras do capital no cerrado: dinâmica e contradições da expansão do agronegócio na região Centro-Oeste, Brasil. Scripta Nova (Revista Electrónica de Geografía y Ciencias Sociales), Barcelona, 21, 507.

Bourdieu, P. (1988). La distinción: critério y bases sociales del gusto. Taurus.

Brioschi L. R. \& Trigo, M. H. B. (1987). Relatos de vida em ciências sociais: considerações metodológicas. Ciência e Cultura, 39 (7) 631-7.

Chayanov, A. V. (1974). La organización de la unidad económica campesina. Ediciones Nueva Visión.

Fritz, S. et al. (2015). Mapping global cropland and field size. Global Change Biology, 21(5), 1980-1992.

Graeub, B. E., Chappell, M. J., Wittman H., Ledermann, R., Kerr, R. B. \& Gemmill-Herrena, B. (2016). The state of Family farms in the world. World Development. $87,1-15$.

Grisa, C., Wez Júnior, V. J. \& Buchweitz, V. D. (2014). Revisitando o Pronaf: velhos questionamentos, novas interpretações. Revista de Economia e Sociologia Rural, 2(52), 323-346.

IBGE. Instituto Brasileiro de Geografia e Estatística. (2010). Censo demográfico 2010 (Piauí). Características da população e dos domicílios. Resultados do universo. IBGE.

IBGE. Instituto Brasileiro de Geografia e Estatística. (2021). Cidades e estados: Uruçuí. https://www.ibge.gov.br/cidades-e-estados/pi/urucui.html.

Incra. Instituto Nacional de Colonização e Reforma Agrária. (2013). Estrutura fundiária do Piauí por município. Teresina: Incra (Superintendência regional do Piauí - SR 24). 
Lênin, V. I. (1982). O desenvolvimento do capitalismo na Rússia: o processo de formação do mercado interno para a grande indústria. Abril Cultural.

Leff, E. (2009). Ecologia, capital e cultura: a territorialização da racionalidade ambiental. Vozes.

Manzini, E. J. (2006). Considerações sobre a entrevista para a pesquisa social em educação especial: um estudo sobre análise de dados. In: Jesus, D. M., Baptista, C. R., Victor, S. L. Pesquisa e educação especial: mapeando produções. UFES, p. 361-386.

Martins, J. S. (2012). A sociedade vista do abismo: novos estudos sobre exclusão, pobreza e classes sociais. (4a ed.), Vozes.

Moraes, M. D. C. (2006). Do destino pastoril à vocação agrícola: modernização agrícola dos cerrados e inflexões discursivas nas narrativas mestras do Piauí. In: Elias, D. \& Pequeno, R. (Orgs.). Difusão do agronegócio e novas dinâmicas socioespaciais. Fortaleza: Banco do Nordeste do Brasil, $173-209$.

Moraes, M. D. C. (2009). Um povo do cerrado entre baixões e chapadas: modo de vida e crise ecológica de camponeses(as) nos cerrados do sudoeste piauiense. In: Godoi, E. P. de, Menezes, M. A. de, Marin, R. A. (Orgs.). Diversidade do campesinato: expressões e categorias. v. 2 (estratégias de reprodução social). São Paulo: Unesp, Brasília: Núcleo de Estudos Agrários e Desenvolvimento Rural, 131-161.

Morais, R. C. S. (2021). Mapa de localização espacial de Uruçuí/PI. Teresina. Mapa color. 1:60 km.

Mucchieli, A. (1996). Dictionnaire des méthodes qualitatives em sciences humaines. Armand Colin.

Orlandi, E. P. (2000). Análise do discurso: princípios e procedimentos. Pontes.

Rede Social de Justiça e Direitos Humanos. (2018). Imobiliárias agrícolas transnacionais e a especulação como terras na região do MATOPIBA. São Paulo: Outras Expressões.

Redin, E. (2012). Estratégias de reprodução na agricultura familiar: um campo em permanente construção. Acta Geográfica, 6(13), $155-173$.

Sabourin, E. (2009). Camponeses do Brasil: entre a troca mercantil e a reciprocidade. Garamond.

Sahlins, M. (1979). Cultura e razão prática. Zahar Editores.

Sahlins, M. (1983). Sociedades tribais. Zahar Editores, 1983.

Sawyer, D. (2008). Climate change, biofuels and eco-social impacts in the Brazilian Amazon and Cerrado. Philosophical Transactions of the Royal Society B, $362,1747-1752$.

Schneider, S. (2003). Teoria social, agricultura familiar e pluriatividade. Revista Brasileira de Ciências Sociais, 18(51), 99-122.

Silva, A. J. (2016). Agricultura familiar e a desterritorialização/desterritorialização/reterritorialização provocada pelo agronegócio no cerrado piauiense: hibridismo sociocultural marginal em Uruçuí. 325 fls. Tese (Doutorado), Programa de Pós-Graduação em Desenvolvimento e Meio Ambiente, Universidade Federal do Piauí, Teresina.

Silva, A. J. (2021). Os desafios da agricultura familiar do cerrado piauiense. Revista da Academia de Ciências do Piauí, 2(2), 171-190.

Silva, A. J., Monteiro, M. S. L. \& Barbosa, E. L. (2016). Agricultura familiar: perspectiva de um debate que não esgota. Campo-Território, 11(24), 70-98.

Silva, A. J., Monteiro, M. S. \& Barbosa, E. L. (2018). Implicaciones sociales y ambientales del agronegócio em Uruçuí, Piauí, Brasil. Sociedade e Território, 29(2) 115-131.

Silva, A. J., Monteiro, M. S. L. \& Barbosa, E. L. (2020). From modernization to deterritorialization: dynamics and dilemmas of agricultural work in the Cerrado of Piauí, Brazil. Redes, 25(2), 744-761.

Silva, M. \& Hespanhol, R. A. M. (2016). As estratégias de reprodução social dos agricultores familiares das comunidades rurais do município de Catalão (GO). Geo UERJ, 29, 402-430.

Tonneau, J. P., Aquino, J. R. \& Teixeira, O. A. (2005a). Modernização da agricultura familiar e exclusão social: o dilema das políticas agrícolas. Cadernos de Ciência e Tecnologia, 22(1), 67-82.

Tonneau, J. P., Aquino, J. R. \& Teixeira, O. A. (2005b). Modernisation de l'agriculture familiale et exclusion: le dilemme des politiques agricoles. Cahiers Agricultures, 14(1), 30-34.

Triviños, A. N. S. (1987). Introdução à pesquisa em ciências sociais: a pesquisa qualitativa em educação. Atlas.

Wanderley, M. N. B. (2003). Agricultura familiar e campesinato: rupturas e continuidade. Estudos Sociedade e Agricultura, 21 , $42-61$.

Wanderley, M. N. B. (2009). O mundo rural como espaço de vida: reflexões sobre a propriedade da terra, agricultura familiar e ruralidade. Editora da UFRGGS.

Wolf, E. R. (1976). Sociedades camponesas. (2a ed.), Zahar Editores. 